\title{
Effects of the Amount of Dietary Nitrates Consumption on Endurance Performance 膡食補充硝酸監對新加坡休閒運動員的酎力運動表现的影響
}

\author{
Vera WAH Sarah KOH Denise NG \\ Grace WANG Steven QUEK \\ Cedar Girls' Secondary School, Singapore
}

\section{苹怡范諧惠怡黃佳敏}

笔世嘉郭進輝

新加坡四德女子中學

\begin{abstract}
The current study examined the effects of dietary nitrates consumption on endurance performance of recreational athletes in Singapore. The consumption of dietary nitrates has been shown to reduce whole body oxygen cost of submaximal exercise and enhance tolerance to high intensity exercise. Beetroot, which is concentrated in dietary nitrates, is a popular natural food that has been associated with enhancement of endurance performance. Majority of studies on the effects of beetroot consumption on endurance performance have been carried out using $500 \mathrm{ml}$ of beetroot juice. To make the juice more palatable, and hence encourage consumption by the young athletes, this study used $250 \mathrm{ml}$ of beetroot juice, mixed with $250 \mathrm{ml}$ of apple and orange juice. 23 subjects (10 males and 13 females aged between 12 and 24) were recruited for the study. Subjects performed the Multi-stage Fitness Test (MST) on two separate days after consuming $500 \mathrm{ml}$ of Apple and Orange ( $\mathrm{AO}$, Control Group) juice or Apple, Beetroot and Orange ( $\mathrm{ABO}$, Experimental Group) juice. The VO2 max obtained from both tests were compared using a Paired Sample t-test. Paired Sampled $t$-test $(t=-0.08, p<0.05)$ showed that there was no significant difference between the $\mathrm{VO} 2 \max$ of the experiment group and the $\mathrm{VO} 2 \max$ of the control group. Results of the present study suggests that $250 \mathrm{ml}$ of beetroot juice combined with $250 \mathrm{ml}$ of apple and orange juice did not result in significant differences in endurance performance.
\end{abstract}

\section{摘 要}

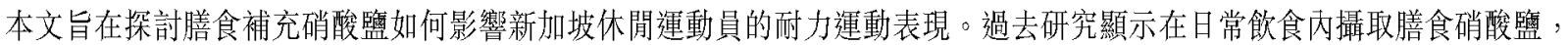

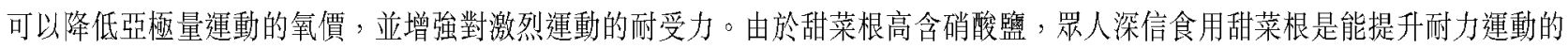

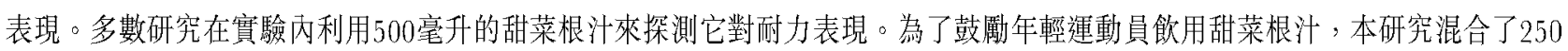
毫升的甜莱汁及250毫升的蘋果和橙汁。23名12歲至24歲的休閒運動員（10名男性與13名女性）參與本研究。賽驗在分別兩天喝 了500毫升蘋果與橙汁（控制組）或500毫升頻果，橙與紅甜莱根汁（實驗組）之後，進行了多階段體能測圾(Multi-stage Fitness

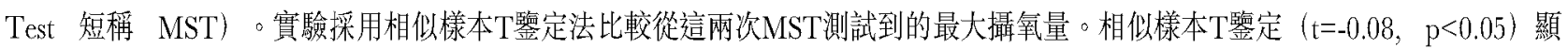
示控制組與實驗組的VO2 max之閌没有顯著的差異。因此, 本研究顯示 250 毫升甜菜根加人 250 毫升頻果和橙混合汁對耐力運動 表現没有顯著的影響。

\section{Introduction}

Consumption of dietary nitrates has been shown to reduce whole body oxygen cost of submaximal exercise and enhance tolerance to high intensity exercise (Bailey et al., 2009). According to Jones (2014), consumption of nitrates, which is concentrated in green leafy vegetables and beetroot, could have positive effects on the mitochondria within our cells, reducing the oxygen cost during exercise. This means that with higher nitrate 
concentration in the body system, the same amount of muscular force can now be generated using less oxygen, improving muscle efficiency and allowing athletes to exercise at a higher power output.

Beetroot is one of the more popular natural foods considered to help athletic performance. In a study by Lansley et al. (2011), nine competitive male cyclists consumed $500 \mathrm{ml}$ of beetroot juice which contained approximately $6.2 \mathrm{mmol}$ of nitrates before a cycling time trial displayed an improvement in cycling economy. The study indicated that the physiological effects of beetroot juice consumption was due to the nitrate content in beetroot.

In a study conducted by Wyle et al. (2013), the dose-response relationship between the volume of beetroot juice consumed and the physiological effects elicited was investigated, using $70 \mathrm{ml}, 140 \mathrm{ml}$ and $280 \mathrm{ml}$ of concentrated beetroot juice. The study concluded that consumption of beetroot juice containing approximately 5 -8mmol of inorganic nitrate, induced an increase in plasma nitrite concentration, reduced blood pressure, and may positively affect the physiological responses to exercise.

However, there were several studies which produced contradicting results. A study by Cermak et al. (2012) on the effect of beetroot juice with positive results was conducted in physically active people or recreational athletes, but failed on competitive athletes. Well-trained athletes demonstrate increased endothelial function, vascular control, greater blood flow in muscles and are more metabolically efficient (reduced consumption of oxygen for a given workload). Since the ergogenic effects of dietary nitrates consumption are primarily induced by enhancing metabolic efficiency, there is a possibility that there is less room for further improvement of exercise oxygen cost and performance in athletes (Zafeiridis A, 2014).

While the consumption of beetroot juice have been found to enhance performance, there is a general perception that the taste of beetroot juice, by itself, is unpalatable, especially to younger athletes. To circumvent the problem, one possible solution could be to blend other fruits with beetroot. The extant literature suggests that an amount of $500 \mathrm{ml}$ of pure beetroot juice could bring about enhanced endurance performance. To add additional fruit juice to the recommended quantity of beetroot juice would mean consuming a large amount of fruit juice prior to physical activity. In this study, we experimented with a beverage that contained $250 \mathrm{ml}$ of beetroot juice and $250 \mathrm{ml}$ of apple and orange juice.

We hypothesized that our concoction of fruit juice containing beetroot, apple, and orange would enhance endurance performance of recreational athletes in Singapore.

Would athletes still be able to reap the same benefits consuming a reduced amount of beetroot juice at $250 \mathrm{ml}$ ?

This study sets out to replicate the investigation of the effects of dietary nitrates consumption on endurance performance on the Singaporean recreational athletes, but with a reduced amount of beetroot.

\section{Methodology}

\section{Subjects}

A total of 23 subjects (10 male and 13 female aged between 12 and 24) performed the Multi-stage Fitness Test (MST) on two separate days after consuming $500 \mathrm{ml}$ of Apple and Orange (AO, Control Group) juice or $500 \mathrm{ml}$ of Apple, Beetroot and Orange (ABO, Experimental Group) juice.

11 subjects drank $\mathrm{ABO}$ juice while 12 subjects drank $\mathrm{AO}$ juice on the first day of the test. There was a crossover on the second day of the test and the 11 subjects drank AO juice while the 12 subjects drank $\mathrm{ABO}$ juice. The two tests were conducted with a 2-day rest in between to facilitate recovery, as suggested by Rhea et al., (2003).

Subjects consumed the juice 2.5 hours before performing the MST, as research has shown that peak nitrate levels occur 2-3 hours after consumption (Wylie et al., 2013).

\section{Multi-stage Fitness Test (MST)}

The MST is a maximal test used to evaluate cardiovascular fitness and measure one's VO2 max. The test consists of 23 levels, with each level lasting approximately 1 minute. Each level comprises of a series 
of 20-meter shuttles where the starting speed is $8.5 \mathrm{~km}$ / hr and increases by $0.5 \mathrm{~km} / \mathrm{hr}$ at each level (Leger and Lambert, 1982). Maximal oxygen uptake (VO2 max) is the measurement of the highest rate of oxygen consumption during maximal exercise. It is an indicator of one's maximal ability to utilise oxygen in the aerobic production of energy (Southard and Pugh, 2004).

Subjects ran back and forth between the 20-meter shuttles, in time with the beep sounds from an online MST audio file downloaded from Topend Sports. Each successful run of the 20 meter distance was a completion of the shuttle. Subjects were informed if they did not reach the end of the shuttle line in time once. The test was terminated when they were unable to follow the set pace of the "beeps" for two successive shuttles, and or stopped voluntarily. The number of stages and levels completed by the subject was recorded (Aziz et al., 2005). The subjects' VO2 max was then calculated using an online calculator developed by Topend Sports from the published tables in Ramsbottom et al. (1988). The subject's results and VO2 max calculated from the two tests were then compared.

\section{Results}

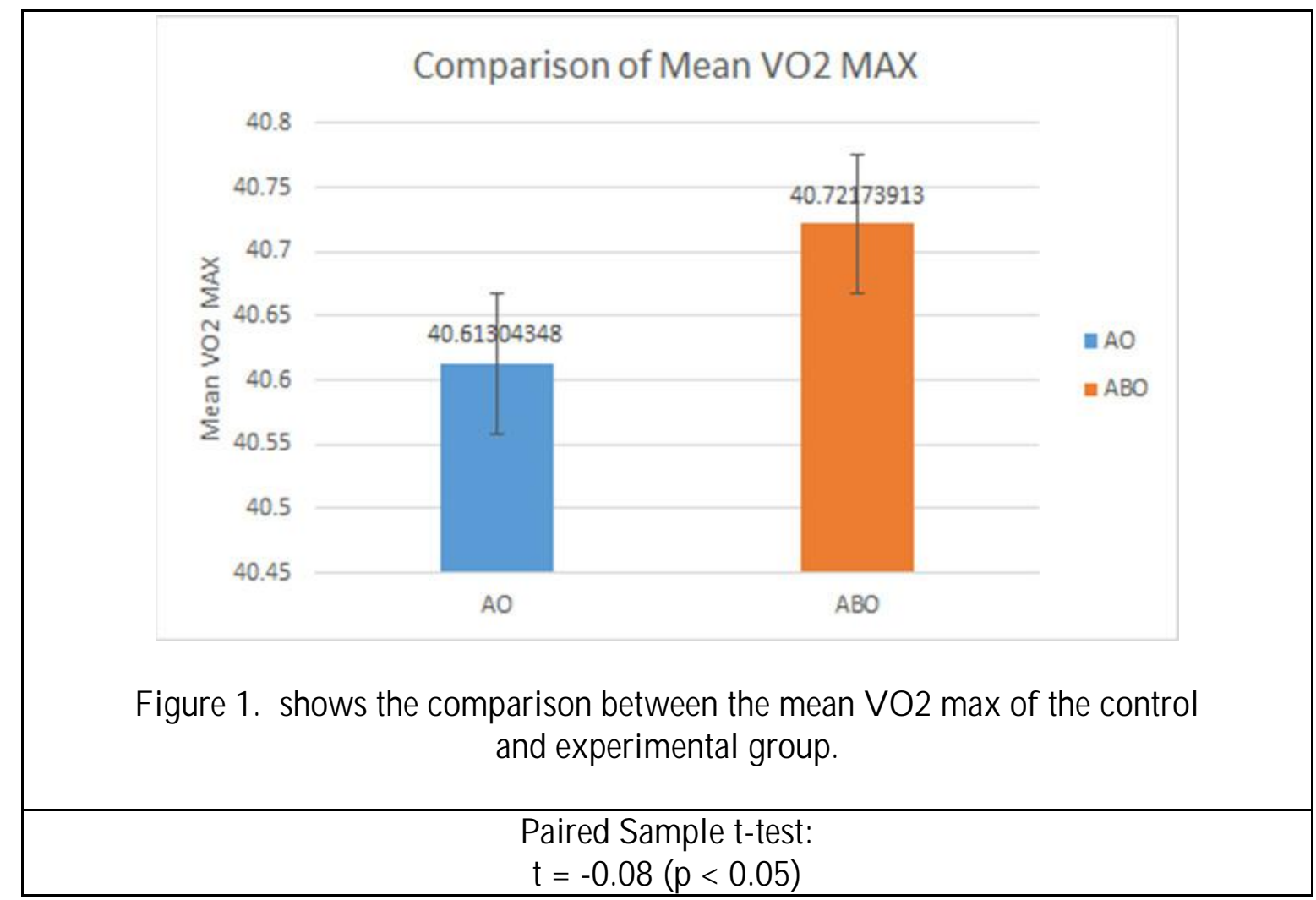

Paired Sampled t-test $(t=-0.08, p<0.05)$ shows that there is no significant difference between the VO2 max of the experiment group (mean $=40.72 \mathrm{ml} / \mathrm{kg} / \mathrm{min}, \mathrm{SD}=12.73$ ) and the VO2 max of the control group $($ mean $=40.61 \mathrm{ml} / \mathrm{kg} / \mathrm{min}, \mathrm{SD}=13.75)$.

\section{Discussion}

The results show that there is no significant difference between the $\mathrm{VO} 2 \max$ of the experiment group consuming Apple, Beetroot, Orange juice and the control group consuming Apple and Orange juice. The reduced amount of beetroot in this study fails to deliver the result of enhanced endurance performance.
A possible reason for this study's failure to deliver the result of enhanced endurance performance may be due to the amount of nitrates in $250 \mathrm{ml}$ of beetroot juice which may be insufficient ( $<5 \mathrm{mmol}$ of nitrates) to induce ergogenic effects dietary nitrates consumption does. The supplementation of $250 \mathrm{ml}$ of beetroot juice, with $250 \mathrm{ml}$ other fruit juices, does not give the same outcome as studies using $500 \mathrm{ml}$ of beetroot juice. 


\section{Suggestion for future research}

1. What the subjects do in terms of training and their diet during the two days between the two MSTs might have an impact on the findings of the study. There may be a need to better control the activity and diet of the subjects in future studies.

2. The Multi-stage Fitness Test is a maximal test and the results could be affected by the level of motivation of the subjects. Ways to enhance motivation should be considered.

3. Future research could explore the effects of endurance performance with increasing amounts of beetroot. $(300 \mathrm{ml}, 350 \mathrm{ml}, 400 \mathrm{ml}$ etc.)

\section{Conclusion}

Consuming $250 \mathrm{ml}$ of beetroot juice (dietary nitrates) 2.5 hours before a beep test does not enhance the endurance performance of the Singaporean recreational athletes. The reduction in the amount of beetroot juice, and the corresponding reduction in the inorganic nitrate in the juice failed to induce the positive physiological responses to exercise that $500 \mathrm{ml}$ of beetroot juice have been found to provide.

\section{References}

Aziz, A. R., Tan, H. Y., \& The, K. C. (2005). A pilot study comparing two field tests with the treadmill run test in soccer players. Journal of Sports Science and Medicine, 4(2), 105-112

Bailey, S. J., Winyard, P. G., Vanhatalo, A., Blackwell, J. R., Dimenna, F. J., Wilkerson, D. P., Tarr, J., Benjamin, N. \& Jones, A. M. (2009). Dietary nitrate supplementation reduces the $\mathrm{O} 2$ cost of low-intensity exercise and enhances tolerance to high-intensity exercise in humans. Journal of Applied Physiology, 107(4), 114455.

Cermak, N. M., Res, P., Stinkens, R., Lundberg, J. O., Gibala, M. J., \& van Loon, L. J. C. (2012). No Improvement in endurance performance after a single dose of beetroot juice. International Journal of Sport Nutrition \& Exercise Metabolism, 22 (6), 470-478.
Jones, A. M. (2014). Dietary Nitrate Supplementation and Exercise Performance. Sports Med. 44(Suppl 1), $35-45$.

Jones, A. M., Vanhatalo, A., \& Bailey, S. J. (2013). Influence of dietary nitrate supplementation on exercise tolerance and performance. Nestle Nutrition Institute Workshop Series. 75, 27-40.

Lansley, K. E, Winyard, P. G, Bailey, S. J., Vanhatalo, A. Wilkerson, D. P., Blackwell, J. R., Gilchrist, M., Benjamin, N., \& Jone, A. M. (2011). Acute dietary nitrate supplementation improves cycling time trial performance. Medicine and Science in Sports and Exercise. 43(6), 1125-31.

Leger, L. A., \& Lambert, J. (1982). A maximal multistage 20-m shuttle run test to predict $\mathrm{VO} 2$ max. European Journal of Applied Physiology. 49(1), $1-12$.

Ramsbottom R, Brewer J and Williams C. (1988). A progressive shuttle run test to estimate maximal oxygen uptake. British Journal of Sports Medicine. 22(4), 141-144.

Rhea, M. R., Alvar, B. A, Burkett, L. N., \& Ball, S. D. (2003). A meta-analysis to determine the dose response for strength development. Department of Exercise and Wellness, Arizona State University, Mesa, AZ and Department of Nutritional Sciences, University of Missouri, Columbia, MO. 35(3), 45664.

Southard, T. L., \& Pugh, J. W. (2004). Effect of hydration state on heart rate-based estimates of VO2max. Journal of Exercise Physiology Online. $7(1), \quad 19-25$

Wylie, L. J, Kelly, J, Bailey, S. J., Blackwell, J. R., Skiba, P. F., Winyard, P. G., Jeukendrup, A. E., Vanhatalo, A., \& Jones, A. M. (2013). Beetroot juice and exercise: pharmacodynamic and doseresponse relationships. Journal of Applied Physiology. $115(3), 325-36$.

\section{Correspondence}

Steven Quek Chin Hwee

Email: sq1967@hotmail.com 